\title{
Familial Influences on Mismatch Negativity and Its Association with Plasma Glutamate Level: A Magnetoencephalographic Study in Twins
}

\author{
Yukika Nishimura $^{a}$ Yuki Kawakubo $^{\text {b }}$ Motomu Suga $^{c}$ Kenji Hashimoto ${ }^{d}$ \\ Yuichi Takei $^{\mathrm{e}}$ Kunio Takei $^{f}$ Hideyuki Inoue $^{\mathrm{a}}$ Masato Yumoto ${ }^{g}$ Ryu Takizawa $^{\mathrm{a}}$ \\ Kiyoto Kasai ${ }^{\mathrm{a}}$
}

Departments of a Neuropsychiatry, ${ }^{b}$ Child Neuropsychiatry, and ${ }^{c}$ Rehabilitation, Graduate School of Medicine, The University of Tokyo, Tokyo, d Division of Clinical Neuroscience, Chiba University Centre for Forensic Mental Health, Chiba, ${ }^{e}$ Department of Psychiatry and Neuroscience, Graduate School of Medicine, Gunma University,

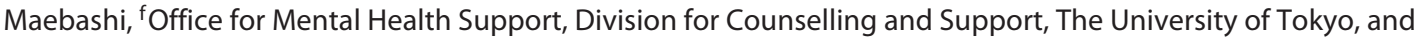
${ }^{9}$ Department of Clinical Laboratory, Graduate School of Medicine, The University of Tokyo, Tokyo, Japan

\section{Key Words}

Glutamate · Magnetoencephalography · Mismatch negativity · Monozygotic twins

\begin{abstract}
Mismatch negativity (MMN) or its magnetic counterpart (magnetic mismatch negativity; MMNm) is regarded as a promising biomarker for schizophrenia. Previous electroencephalographic studies of MMN have demonstrated a moderate-to-high heritability for MMN amplitudes. $\mathrm{N}$-methyl-Daspartate receptor-dependent glutamatergic neurotransmission is implicated in MMN generation. We hypothesized that the differences between identical twins in $\mathrm{MMNm}$ variables might be associated with differences in plasma levels of amino acids involved in glutamatergic neurotransmission. Thirty-three pairs of monozygotic (MZ) and 10 pairs of dizygotic (DZ) twins underwent MMNm recording. The MMNm in response to tone duration changes, tone frequency changes, and phonemic changes was recorded using 204-channel magnetoencephalography. Of these, $26 \mathrm{MZ}$ and $7 \mathrm{DZ}$ twin pairs underwent blood sampling for determi-
\end{abstract}

nation of plasma amino acid levels. MMNm peak strength showed relatively high correlations in both $\mathrm{MZ}$ and $\mathrm{DZ}$ twin pairs. The differences in MMNm latencies tended to correlate with the differences in plasma amino acid levels within $M Z$ pairs, while no significant correlation was observed after the Bonferroni correction. We observed a familial trait in $\mathrm{MMNm}$ strength. The differences in MMN latency in $M Z$ twins might be influenced by changes in glutamate levels and glutamate-glutamine cycling; however, the results need to be replicated.

(c) 2016 S. Karger AG, Basel

\section{Introduction}

Mismatch negativity (MMN) or its magnetic counterpart (magnetic mismatch negativity; $\mathrm{MMNm}$ ) is a component of event-related potentials (ERPs) or the magnetic field elicited by a physically deviant stimulus in a train of standard stimuli. The MMN is regarded as a promising biomarker for schizophrenia (SZ). Electroencephalography (EEG) and magnetoencephalography (MEG) studies

\section{KARGER}

E-Mail karger@karger.com www.karger.com/mnp
(C) 2016 S. Karger AG, Basel

2296-9209/16/0023-0161\$39.50/0 
consistently report reduced MMN amplitudes in patients with SZ $[1,2]$. The MMN amplitude declines across clinical stages including ultra-high risk, first-episode, or chronic SZ [3, 4]. Moreover, first-degree healthy relatives of patients with SZ also exhibit reduced MMN amplitudes $[5,6]$, although exceptions to this have also been reported [7].

Previous EEG studies of MMN have demonstrated a moderate-to-high heritability for MMN amplitudes in 40 monozygotic (MZ) and 30 dizygotic (DZ) twin pairs [8]. In contrast, reliability and heritability for MMN latency were low [8]. Hall et al. [8] performed a structural equation modelling analysis and reported that, other than the estimated heritability, the shared environment component exerted a minimal influence on MMN amplitude and latency, and the components of specific environment and measurement errors accounted for the rest of the variance. However, it is unknown what environmental factors influence the difference in MMN amplitude and latency within twin pairs.

The MMN is thought to reflect glutamatergic neurotransmission mediated by $N$-methyl-D-aspartate(NMDA) type receptors, which plays a central role in long-term potentiation and synaptic plasticity. In healthy individuals, a reduced $M M N$ amplitude in response to administration of the NMDA receptor agonist ketamine demonstrates the involvement of NMDA receptor signalling in MMN generation [9]. We previously reported that genetic variations in metabotropic glutamate receptor 3 , which is involved in regulating synaptic glutamate levels, affect phonemic MMNm in healthy males [10]. Metabotropic glutamate receptors co-activated with NMDA receptors play a significant role in synaptic plasticity [11]. Alterations in NMDA receptors are implicated in the dysregulation of glutamatergic neurotransmission seen in SZ. A metaanalysis of proton magnetic resonance spectroscopy (MRS) studies indicated decreased glutamate and increased glutamine in the medial prefrontal region of patients with SZ [12]. In this context, the MMN is associated with glutamatergic neurotransmission in the brain.

The levels of amino acids involved in glutamatergic neurotransmission in cerebrospinal fluid (CSF) can be estimated from plasma amino acid levels even though they cannot pass through the blood-brain barrier. Glutamate levels in the blood are positively correlated with CSF levels of glutamate in humans $[13,14]$. Compared to healthy controls, patients with psychiatric disorders exhibit reduction in glutamate and D-serine levels both in the peripheral blood [15, 16] and in the CSF [17]. The ratio of glutamine to glutamate in the CSF of first-episode, drug-naive male patients with SZ was significantly higher than that of normal controls [18]. Furthermore, blood-metabolite correlations between MZ twins were strong relative to midparent-offspring and spouse pairs [19], although metabolite levels are affected by nutritional status [20]. Given these previous findings, it may be reasonable to assume that there is an association between the MMN and plasma amino acid levels including glutamate and D-serine.

Therefore, we hypothesized that MMNm strength shows a high similarity and that differences in MMNm within MZ twin pairs are associated with differences in plasma amino acid levels, both due to differences in the neurophysiological phenotype.

In addition, we adopted three auditory stimulus contrasts for our MMN experiments: tone duration change, tone frequency change, and phoneme (speech sound) change. As stated above, many studies have demonstrated an association between clinical stage in patients with SZ and the amplitude of MMNs triggered by two of these contrasts - tone duration change or tone frequency change $[2,4]$. MMNm is also elicited by a change in speech sounds [21] and has been seen as an index of language-specific speech sound traces and learning-induced short-term plasticity. We have shown that in patients with SZ, phonemic MMN/MMNm shows a larger reduction than pure-tone MMN/MMNm in ERP and MEG studies [22, 23].

Thus, to examine the genetic contribution to auditory MMNm, we used MEG to investigate the intra-class correlation coefficients (ICCs) of MMNm variables in $\mathrm{MZ}$ and DZ adult twin pairs. Moreover, we assessed a possible association between the differences of $\mathrm{MMNm}$ variables and plasma amino acid levels to clarify neurophysiological differences within MZ twin pairs.

\section{Materials and Methods}

\section{Participants}

Forty-three same-sex Japanese twin pairs who had been raised together $(n=86)$ were recruited through advertisements on our website and in the newspaper. Participant exclusion criteria were as follows: left-handedness [24], age $>55$ years, opposite-sex twin pair, loss of consciousness for $>5$ min due to head injury, history of any psychiatric disorders assessed by the Mini-International Neuropsychiatric Interview (M.I.N.I.) [25], or first-degree relatives with psychiatric disorders. Zygosity was determined by genotyping for 42 twin pairs by independent experimenters from the MEG measurement. DNA extracted from peripheral leukocytes was genotyped using the Genome-Wide Human SNP Array 6.0 (Affymetrix, Santa Clara, Calif., USA). The zygosity of the remaining twin pair was estimated using a self-report questionnaire [26, 27] because they declined to submit to blood sampling. The analy- 
sis included 33 pairs of MZ twins ( 30 female and 3 male, mean age $=35.4$ years, $\mathrm{SD}=10.4$ ) and 10 pairs of DZ twins ( 9 female and 1 male, mean age $=29.9$ years, $S D=7.0)$. The comparisons of gender ratio ( $\chi^{2}$ tests) and mean age (Student's t tests) showed no significant differences between the MZ and DZ groups $\left[\chi^{2}(1)=0.008\right.$, $\mathrm{p}=0.93$, and $\mathrm{t}(41)=1.55, \mathrm{p}=0.13$, respectively].

Registration within twin pairs was numbered according to the birth order recorded in their maternal and child health handbooks (firstborn, twin 1; second born, twin 2). Three twin pairs without birth order documentation were numbered in the order of contact with the research program as a matter of convenience (first contact, twin 1; second contact, twin 2). Each twin pair completed the MEG experiment, blood sampling, and interview on the same day. We confirmed by interview that the participants and their parents were native speakers of Japanese, a precaution necessitated by the fact that speech sound MMN is affected by the subject's language exposure. In addition, intelligence quotient (IQ) was estimated using the Japanese version of the National Adult Reading Test (JART) [28], which is a reading test of 50 Japanese irregular words, all of which are Kanji (ideographic script) compound words. All participants also participated in a separate near-infrared spectroscopy imaging study [29].

\section{Amino Acid Measurements}

The current study measured levels of plasma amino acids, including glutamate, glutamine, glycine, D-serine, and L-serine, and calculated the glutamine/glutamate ratio and the percentage of Dserine.

Blood sampling for measuring amino acids in the peripheral blood was only performed for participants who provided informed consent. Blood draws were completed just before the MEG session (10 a.m. or 2 p.m. on the same day).

The measurement of glutamate, glutamine, and glycine was carried out using a high-performance liquid chromatography (HPLC) system with fluorescence detection as previously reported [18]. The measurement of total, D- and L-serine plasma levels was performed with a column-switching HPLC system (Shimadzu Corporation, Kyoto, Japan) as previously reported [30, 31]. For the detailed method of amino acid determination, see online supplementary material (for all online suppl. material, see www. karger.com/doi/10.1159/000449426).

The glutamine ratio (glutamine/glutamate) and the percentage of total serine in the $\mathrm{D}$-form $[100 \times(\mathrm{D}$-serine $) /(\mathrm{D}$-serine $+\mathrm{L}$-serine)] were also used as plasma amino acid variables, in addition to levels of glutamate, glutamine, glycine, and D- and L-serine.

\section{Task Procedures}

When participants performed the visual target detection task, the auditory stimuli to elicit MMNm were presented through ear tubes. Participants were instructed to focus on the visual target detection task and ignore the auditory stimuli. In these visual and auditory tasks for eliciting an MMNm response, we adopted our previously described procedures $[10,32]$, which are briefly explained in the following section.

\section{Visual Target Detection Task}

During MEG measurement, pictures (e.g. animal, flower, sweets, landscape, festival, etc.) were continuously presented for $2,000 \mathrm{~ms}$ one by one on the screen in front of the participants. They were asked to ignore the auditory stimuli and press the button im- mediately after target stimulus presentation (e.g. sweets). The target stimuli were randomly presented with a probability of $30 \%$ and were not synchronized with the auditory stimuli presented to elicit the MMNm.

\section{Auditory Task}

MMNm responses were recorded during the auditory task. The auditory stimuli were presented to both ears through the ear tubes ( $80 \mathrm{~dB}$ SPL and a rise/fall time of $10 \mathrm{~ms}$ ). The experiments consisted of two sequences, and each sequence was conducted until 120 deviant stimuli were presented in each condition. One sequence elicits the $\mathrm{MMNm}$ in response to pure tonal changes using two deviant stimuli (standard: 1,000 Hz, $50 \mathrm{~ms}, 83 \%$; duration deviant: $1,000 \mathrm{~Hz}, 100 \mathrm{~ms}, 8.3 \%$; frequency deviant: $1,200 \mathrm{~Hz}, 50 \mathrm{~ms}$, $8.3 \%)$. Another sequence elicits the MMNm in response to phonemic changes using a native Japanese actor's voice (standard: Japanese vowel /a/, $250 \mathrm{~ms}, 90 \%$; deviant: Japanese vowel /o/, $250 \mathrm{~ms}$, $10 \%)$ which was digitalized in NeuroStim System (Neuroscan Inc., Charlotte, N.C., USA). The inter-stimulus interval was set at $445 \pm$ $15 \mathrm{~ms}$. Auditory presentation was conducted using Stim 2 presentation software (Neuroscan Inc.). The presentation order of the two sequences was counterbalanced across the twin pairs, and the same order was presented within twin pairs.

\section{MEG Acquisition}

The MEG signal was measured in a magnetically shielded room using VectorView (Elekta Neuromag, Helsinki, Finland). This machine has 204 first-order planar gradiometers at 102 measuring sites on a helmet-shaped surface that covers the entire scalp. The position of the magnetometer with respect to the head was determined at the beginning of the task under each condition by recording the magnetic fields produced by currents fed into four indicator coils at predetermined locations on the scalp. The recorded MEG data were filtered online with a band-pass filter of 0.03-100 $\mathrm{Hz}$, digitalized at a sampling rate of $512 \mathrm{~Hz}$, and averaged separately in the standard and deviant conditions. When necessary, the MaxFilter program by Elekta, which eliminates electrical signals from sources other than the head, was applied to the MEG signals before averaging. Any data with movement contamination, defined as electro-oculogram $>150 \mu \mathrm{V}$ or MEG exceeding 3,000 fT/ $\mathrm{cm}$, were excluded from the averaging. The averaging period of one trial was $400 \mathrm{~ms}$, including an 80 -ms pre-stimulus baseline. We used a signal-space projection filtering method to cancel external noise. The number of deviant stimuli used in the subsequent analysis was $>100$ for all stimulus conditions. The averaged data were filtered offline with a band-pass filter of $1-20 \mathrm{~Hz}$.

\section{MEG Data Analysis}

Magnetic Counterpart of Global Field Power of MMNm

The MMNm was detected as a difference between the magneticfield transient evoked in response to the deviant stimulus and the transient evoked in response to the standard stimulus. The MMNm curve was calculated using a spherical head model. We adopted two indices of peak strength and latency for the MMNm evaluation. MMNm strength was given as an indication of the magnetic counterpart of the global field power (mGFP). We adopted the mGFP because single sensor data were not stable due to individual differences in the spatiotemporal pattern of MMNm. The mean waveform from the 54 channels over the temporal region was plotted for each hemisphere (right and left) and condition (standard and devi- 
Table 1. Mean peak latencies and mGFP strengths for MMNm variables

\begin{tabular}{|c|c|c|c|c|c|c|c|c|}
\hline & \multicolumn{4}{|c|}{ MZ (33 pairs) } & \multicolumn{4}{|c|}{ DZ (10 pairs) } \\
\hline & \multicolumn{2}{|l|}{ twin 1} & \multicolumn{2}{|c|}{ twin 2} & \multicolumn{2}{|l|}{ twin 1} & \multicolumn{2}{|l|}{ twin 2} \\
\hline & mean & $\mathrm{SD}$ & mean & $\mathrm{SD}$ & mean & $\mathrm{SD}$ & mean & $\mathrm{SD}$ \\
\hline \multicolumn{9}{|c|}{ Phonemic change } \\
\hline \multicolumn{9}{|c|}{ Latency, ms } \\
\hline $\mathrm{L}$ & 165.6 & 21.4 & 155.6 & 23.3 & 169.6 & 14.8 & 162.0 & 22.7 \\
\hline $\mathrm{R}$ & 154.7 & 23.7 & 156.0 & 23.4 & 160.6 & 16.2 & 161.2 & 21.2 \\
\hline \multicolumn{9}{|c|}{$\mathrm{mGFP}, \mathrm{fT} / \mathrm{cm}$} \\
\hline $\mathrm{L}$ & 22.4 & 10.2 & 20.9 & 9.3 & 19.0 & 7.2 & 26.9 & 11.3 \\
\hline $\mathrm{R}$ & 23.3 & 11.3 & 20.4 & 9.4 & 20.6 & 6.4 & 18.6 & 5.6 \\
\hline \multicolumn{9}{|c|}{ Tone duration change ${ }^{1}$} \\
\hline \multicolumn{9}{|c|}{ Latency, ms } \\
\hline $\mathrm{L}$ & 177.7 & 18.7 & 178.4 & 25.0 & 175.3 & 25.3 & 174.3 & 19.7 \\
\hline $\mathrm{R}$ & 175.6 & 26.8 & 183.1 & 24.1 & 166.7 & 14.9 & 183.5 & 24.8 \\
\hline \multicolumn{9}{|c|}{$\mathrm{mGFP}, \mathrm{fT} / \mathrm{cm}$} \\
\hline $\mathrm{L}$ & 17.5 & 8.2 & 18.8 & 7.1 & 18.9 & 11.4 & 24.3 & 14.2 \\
\hline $\mathrm{R}$ & 23.4 & 11.7 & 22.4 & 8.2 & 23.9 & 7.7 & 21.4 & 7.9 \\
\hline \multicolumn{9}{|c|}{ Tone frequency change ${ }^{1}$} \\
\hline \multicolumn{9}{|c|}{ Latency, ms } \\
\hline $\mathrm{L}$ & 139.4 & 28.1 & 130.4 & 29.1 & 153.0 & 26.7 & 136.1 & 21.1 \\
\hline $\mathrm{R}$ & 130.5 & 27.0 & 136.3 & 30.6 & 142.1 & 32.6 & 155.6 & 30.5 \\
\hline \multicolumn{9}{|c|}{$\mathrm{mGFP}, \mathrm{fT} / \mathrm{cm}$} \\
\hline $\mathrm{L}$ & 14.4 & 6.1 & 14.9 & 6.9 & 13.1 & 4.8 & 18.0 & 8.7 \\
\hline $\mathrm{R}$ & 16.4 & 6.1 & 13.2 & 4.6 & 17.0 & 4.1 & 14.7 & 6.3 \\
\hline
\end{tabular}

ant). Next, we calculated the MMNm waveform by subtracting the standard from the deviant waveform. Finally, the mGFP was calculated as the root mean square (RMS) of the differences between the magnetic-field transient evoked in response to the deviant stimulus and the transient evoked in response to the standard stimulus. The inputs to this calculation were the means of the 54 channels covering the temporal region, broken down by hemisphere and condition as previously reported $[10,33]$. The peak latency of each MMNm was determined at the time point of the maximum strength in the mGFP curve between 100 and $250 \mathrm{~ms}[23,34]$.

\section{Statistical Analysis}

We first performed repeated-measures analysis of variance (ANOVA) with years of education and estimated IQ serving as dependent variables, 'zygosity' (MZ and DZ) serving as an independent variable and between-subject factor, and 'twin order' (twin 1 and twin 2) serving as an independent variable and withinsubject factor.

ICCs with a one-way random effects ANOVA design [35] were calculated for MMNm peak strength and latency in each of the three MEG task conditions (phonemic change, tone duration change, and tone frequency change) in each hemisphere (left and right), and by zygosity (MZ and DZ), as an index of similarity. ICC was also calculated for years of education and for estimated IQ.

Next, to clarify the association between differences in neurophysiological indices in MZ twins and differences in blood amino acid levels, Spearman's rank correlation coefficients were calculated for the difference values between MZ twins for each MMNm variable and each amino acid level (glutamate, glutamine, glycine, glutamine/glutamate, D-serine, L-serine, total serine, and D-serine/total serine). The difference values of $\mathrm{MMNm}$ and amino acids were calculated by subtracting the value of the twin with the smaller MMNm from the value of the twin with the larger MMNm. We also calculated the Spearman's rank correlation coefficients between each MMNm variable and each amino acid level across MZ individuals $(n=52)$. Additionally, we performed multiple regression analysis when significant correlations were observed. Each MMNm variable was considered a dependent variable, and each amino acid value, age, sex $($ male $=1$, female $=2)$, twin pair $($ No. 1-26), and amino acid assay time (No. 1-3) was considered an independent variable. In cases where an outlier was found by the SmirnovGrubbs test, we re-ran the analysis with the outlier excluded.

Statistical significance was set at $\mathrm{p}<0.05$. We adopted the Bonferroni method to correct for multiple comparisons $(\mathrm{p}<0.002=$ $0.05 / 24$ [zygosity (2) $\times$ MMN condition $(3) \times$ hemisphere $(2) \times$ MMNm index (2)]) in the ICC calculation. The Bonferroni correction method was also adopted for the analysis of correlations between the absolute values of the MMNm indices and the amino acid values $(\mathrm{p}<0.0005=0.05 / 96$ [amino acid value $(8) \times \mathrm{MMN}$ condition (3) $\times$ hemisphere $(2) \times$ MMNm index (2)]). All statisti$\mathrm{cal}$ analyses were performed using IBM SPSS Statistics version 21 (IBM Corp., Armonk, N.Y., USA). 


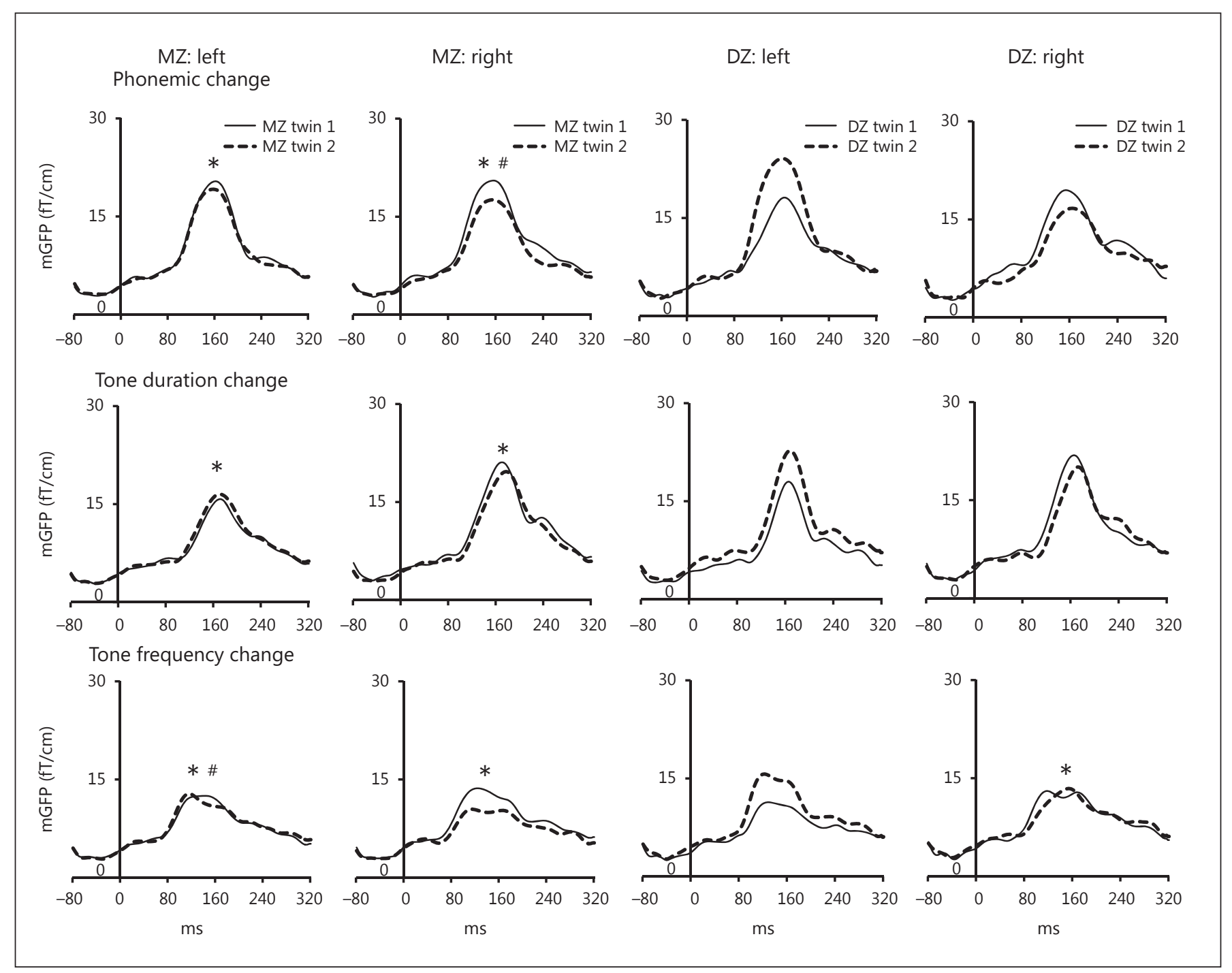

Fig. 1. Grand mean mGFP waveforms of phonemic, tone-duration, and tone-frequency MMNm for the left and right hemisphere in MZ (left 6 graphs) and DZ twins (right 6 graphs). Solid lines represent data for twin 1, and dashed lines represent data for twin $2 .{ }^{*} \mathrm{p}<0.05$, twin 1 vs. twin 2 , in the maximum mGFP strength; ${ }^{*} \mathrm{p}<0.05$, twin 1 vs. twin 2, in the latency of peak MMNm.

\section{Results}

\section{Twin Similarity}

A repeated-measures ANOVA with 'zygosity' and 'twin order' revealed no significant differences for main effects. Moreover, no significant differences were found for interactions with years of education (MZ twin 1, mean $=14.6$ years, $\mathrm{SD}=1.7 ; \mathrm{MZ}$ twin 2 , mean $=14.7$ years, $\mathrm{SD}=1.8$; $\mathrm{DZ}$ twin 1 , mean $=15.5$ years, $\mathrm{SD}=1.8$; $\mathrm{DZ}$ twin 2 , mean $=15.7$ years, $\mathrm{SD}=1.2$ ). Furthermore, no differences were found for interactions with estimated IQ as assessed by JART ( $\mathrm{MZ}$ twin 1 , mean $=105.2, \mathrm{SD}=7.6$;
$\mathrm{MZ}$ twin 2, mean $=106.0, \mathrm{SD}=8.2 ; \mathrm{DZ}$ twin 1 , mean $=$ 101.8, $\mathrm{SD}=6.1 ; \mathrm{DZ}$ twin 2, mean $=101.4, \mathrm{SD}=4.5$ ).

During the MEG measurement, the mean accuracy rates and the mean reaction times for the visual detection task were $96.4 \%(\mathrm{SD}=4.3)$ and $599 \mathrm{~ms}(\mathrm{SD}=144)$ in the phonemic change sequence, and $95.8 \%(\mathrm{SD}=7.1)$ and $595 \mathrm{~ms}(\mathrm{SD}=105)$ in the pure-tonal change sequence, respectively. With regard to $\mathrm{MMNm}$ variables, the mean and SD of latency and mGFP strength in each condition and twin are presented in table 1. Grand mean mGFP waveforms in each condition and twin are shown in figure 1. Only $32 \mathrm{MZ}$ pairs were analysed in the pure-tone 
Table 2. Intra-class correlation coefficients for each $\mathrm{MMNm}$ variable

\begin{tabular}{|c|c|c|c|c|c|c|c|c|}
\hline & \multicolumn{4}{|c|}{ MZ (33 pairs) } & \multicolumn{4}{|c|}{ DZ (10 pairs) } \\
\hline & \multirow[t]{2}{*}{ ICC } & \multicolumn{2}{|c|}{$95 \% \mathrm{CI}$} & \multirow[t]{2}{*}{$\mathrm{p}$ value } & \multirow[t]{2}{*}{ ICC } & \multicolumn{2}{|c|}{$95 \% \mathrm{CI}$} & \multirow[t]{2}{*}{$\mathrm{p}$ value } \\
\hline & & lower & upper & & & lower & upper & \\
\hline Educational level, years & 0.55 & 0.27 & 0.75 & $<0.001$ & 0.39 & -0.25 & 0.80 & 0.107 \\
\hline Estimated IQ & 0.66 & 0.42 & 0.82 & $<0.001$ & -0.35 & -0.78 & 0.31 & 0.858 \\
\hline \multicolumn{9}{|l|}{ MMNm variables } \\
\hline \multicolumn{9}{|l|}{ Phonemic change } \\
\hline \multicolumn{9}{|l|}{ Latency, ms } \\
\hline $\mathrm{L}$ & -0.03 & -0.36 & 0.31 & 0.567 & 0.32 & -0.32 & 0.77 & 0.160 \\
\hline $\mathrm{R}$ & 0.38 & 0.05 & 0.64 & 0.013 & 0.25 & -0.39 & 0.74 & 0.219 \\
\hline \multicolumn{9}{|l|}{$\mathrm{mGFP}, \mathrm{fT} / \mathrm{cm}$} \\
\hline $\mathrm{L}$ & 0.76 & 0.57 & 0.87 & $<0.001^{\#}$ & 0.18 & -0.45 & 0.70 & 0.288 \\
\hline $\mathrm{R}$ & 0.70 & 0.48 & 0.84 & $<0.001^{\#}$ & 0.35 & -0.29 & 0.79 & 0.133 \\
\hline \multicolumn{9}{|l|}{ Tone duration change ${ }^{1}$} \\
\hline \multicolumn{9}{|l|}{ Latency, ms } \\
\hline $\mathrm{L}$ & 0.18 & -0.18 & 0.49 & 0.163 & 0.85 & 0.54 & 0.96 & $<0.001$ \\
\hline $\mathrm{R}$ & 0.03 & -0.31 & 0.37 & 0.424 & -0.75 & -0.93 & -0.27 & 0.996 \\
\hline \multicolumn{9}{|l|}{$\mathrm{mGFP}, \mathrm{fT} / \mathrm{cm}$} \\
\hline L & 0.38 & 0.04 & 0.64 & 0.015 & 0.28 & -0.36 & 0.75 & 0.194 \\
\hline $\mathrm{R}$ & 0.48 & 0.16 & 0.70 & 0.002 & 0.25 & -0.39 & 0.74 & 0.216 \\
\hline \multicolumn{9}{|l|}{ Tone frequency change ${ }^{1}$} \\
\hline \multicolumn{9}{|l|}{ Latency, ms } \\
\hline $\mathrm{L}$ & 0.38 & 0.05 & 0.64 & 0.013 & -0.37 & -0.78 & 0.29 & 0.871 \\
\hline $\mathrm{R}$ & 0.11 & -0.24 & 0.44 & 0.265 & 0.05 & -0.55 & 0.63 & 0.438 \\
\hline \multicolumn{9}{|l|}{$\mathrm{mGFP}, \mathrm{fT} / \mathrm{cm}$} \\
\hline $\mathrm{L}$ & 0.40 & 0.07 & 0.65 & 0.010 & 0.24 & -0.40 & 0.73 & 0.230 \\
\hline $\mathrm{R}$ & 0.42 & 0.10 & 0.67 & 0.006 & 0.65 & 0.11 & 0.90 & 0.012 \\
\hline
\end{tabular}

condition (duration and frequency deviants) because we could not complete the experiment for $1 \mathrm{MZ}$ female twin pair owing to a mechanical problem.

The ICC scores of years of education, estimated IQ, and each $\mathrm{MMNm}$ variable are presented in table 2. Years of education and estimated IQ were only significantly correlated for MZ twins. For the MMNm, the ICCs of the maximum mGFP strength in MZ showed moderateto-high correlation in all conditions and hemispheres (ICC $=0.38-0.76$; table 2). The mGFP values in DZ showed similar but slightly lower correlations in all conditions and hemispheres (ICC $=0.18-0.65)$. The ICCs of the latencies showed low correlations in $\mathrm{MZ}$ ( $\mathrm{ICC}=-0.03$ to 0.38 ) and DZ (ICC $=-0.75$ to 0.32 ), except for the ICC of the latency for tone duration change in the left hemisphere in DZ twins ( ICC = 0.85). After Bonferroni correction, we found a significant correlation for $2 \mathrm{MMNm}$ indices in MZ (table 2).
MEG Molecular Correlations with between-Twin Difference Values for MZ Twins

Of the 43 twin pairs with MEG measurements, $26 \mathrm{MZ}$ (25 female and 1 male) and 7 DZ (6 female and 1 male) twin pairs underwent blood sampling to examine plasma amino acid levels (table 3 ).

We calculated Spearman's rank correlation coefficients between the values of differences between MZ twins to examine whether the variable neurophysiological indices in MZ twins were associated with differences in blood amino acid levels. Our analysis revealed that twins with longer latency of phonemic change in the left hemisphere relative to their co-twins tended to have higher levels of glutamate $(\rho=0.472, p=0.015$; fig. $2 a)$ and lower glutamine/glutamate values $(\rho=-0.405, p=0.04$; fig. 2b). In contrast, twins with longer latency of phonemic change in the right hemisphere relative to their cotwins tended to have higher glycine values $(\rho=0.488, p=$ 
Table 3. Mean plasma amino acid levels in MZ and DZ twins

\begin{tabular}{|c|c|c|c|c|c|c|c|c|}
\hline \multirow[t]{3}{*}{ Amino acids } & \multicolumn{4}{|c|}{ MZ twins (26 pairs) } & \multicolumn{4}{|c|}{ DZ twins (7 pairs) } \\
\hline & \multicolumn{2}{|l|}{ twin 1} & \multicolumn{2}{|l|}{ twin 2} & \multicolumn{2}{|l|}{ twin 1} & \multicolumn{2}{|l|}{ twin 2} \\
\hline & mean & $\mathrm{SD}$ & mean & SD & mean & $\mathrm{SD}$ & mean & $\mathrm{SD}$ \\
\hline D-serine, $\mu \mathrm{M}$ & 1.06 & 0.31 & 1.12 & 0.26 & 0.99 & 0.3 & 1.11 & 0.29 \\
\hline L-serine, $\mu \mathrm{M}$ & 124.01 & 58.12 & 119.41 & 32.77 & 105.4 & 22.34 & 115.05 & 19.92 \\
\hline Total serine, $\mu \mathrm{M}$ & 125.07 & 58.18 & 120.54 & 32.88 & 106.38 & 22.53 & 116.16 & 20.09 \\
\hline Relative D-serine & 0.0094 & 0.0037 & 0.0097 & 0.0026 & 0.0093 & 0.0022 & 0.0096 & 0.0021 \\
\hline Glutamine, $\mu \mathrm{M}$ & 485.07 & 93.49 & 483.32 & 84.40 & 399.55 & 66.71 & 448.71 & 101.31 \\
\hline Glycine, $\mu \mathrm{M}$ & 244.08 & 86.43 & 229.81 & 56.73 & 195.04 & 37.32 & 229.72 & 62.83 \\
\hline Glutamate, $\mu \mathrm{M}$ & 60.23 & 25.22 & 53.81 & 18.14 & 64.46 & 24.66 & 66.18 & 20 \\
\hline Glutamine/glutamate & 8.99 & 2.99 & 9.61 & 2.54 & 7.07 & 3.02 & 7.42 & 2.78 \\
\hline
\end{tabular}

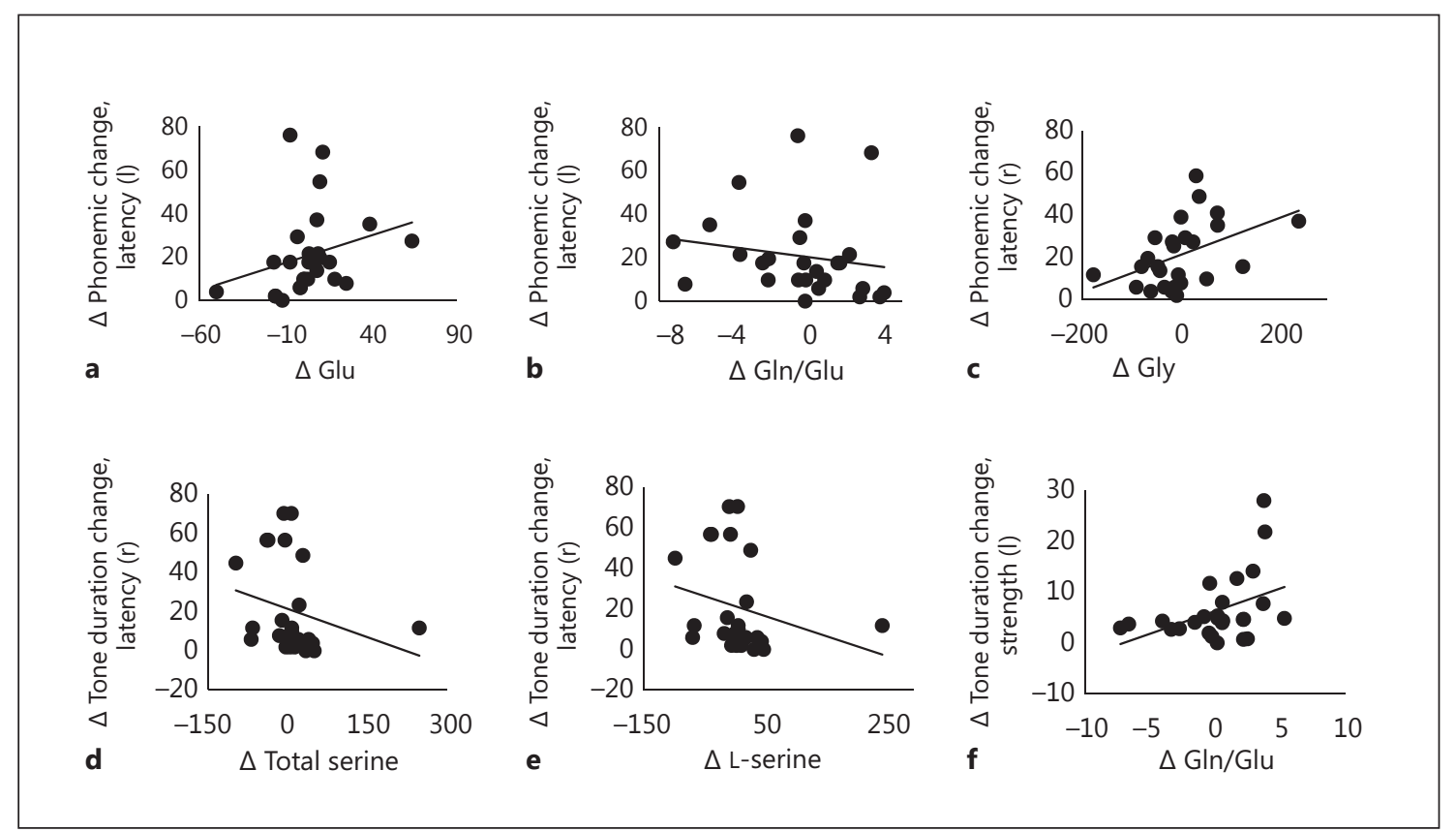

Fig. 2. Scatterplot depicting the significant correlation between the values of the differences between MZ twins in the MMNm group and the corresponding amino acid level differences. The units of the mGFP latency, strength, and amino acid value are $\mathrm{ms}, \mathrm{fT} / \mathrm{cm}$, and $\mu \mathrm{M}$, respectively. $\mathrm{l}=\mathrm{Left} ; \mathrm{r}=$ right; Glu = glutamate; Gln = glutamine; Gly = glycine.

0.011; fig. 2c). Twins with higher latency of tone duration change in the right hemisphere relative to their co-twins tended to have lower total serine $(\rho=-0.419, \mathrm{p}=0.033$; fig. $2 \mathrm{~d}$ ) and L-serine $(\rho=-0.421, \mathrm{p}=0.032$; fig. $2 \mathrm{e})$. Twins with larger values for mGFP strength of tone duration change in the left hemisphere relative to their co-twins tended to have higher glutamine/glutamate values $(\rho=$ $0.460, p=0.018$; fig. 2f). The correlation analyses which excluded outliers identified by the Smirnov-Grubbs test revealed similar results. The correlation analysis across individuals revealed significant correlations for $14 \mathrm{com}$ binations of MMNm variables and amino acid values. Regression analyses revealed significant associations between $\mathrm{mGFP}$ latency of tone duration change and relative $\mathrm{D}$-serine values [model: adjusted $\mathrm{R}^{2}=0.277, \mathrm{p}=0.001 ; \beta$ $($ relative D-serine $)=0.355, \mathrm{p}=0.01 ; \beta($ age $)=-0.127, \mathrm{p}=$ 
$0.309 ; \beta($ sex $)=-0.232, \mathrm{p}=0.09 ; \beta$ (twin pair $)=0.43, \mathrm{p}=$ $0.069 ; \beta$ (assay time) $=-0.464, \mathrm{p}=0.047]$. No significant associations were observed for the remaining 13 combinations. After Bonferroni correction, no significant correlations were observed.

\section{Discussion}

\section{Familial Influences on the Maximum MMNm}

Amplitude

Our findings demonstrate that MMNm peak strength correlates highly in $\mathrm{MZ}$ twin pairs. The high similarity of maximum MMN amplitude in MZ twins is consistent with previous ERP studies $[8,36]$. These results suggest genetic contributions to the MMNm. In particular, the maximum MMNm strength of the left hemisphere in the phonemic change condition showed the highest ICC in MZ twin pairs. The MMN/MMNm amplitude elicited with speech sounds exhibited a left hemisphere dominance. Naatanen et al. [21] reported that the MMNm was larger in the left than in the right hemisphere when a deviant stimulus was used as a prototype in a Finnish language study, and they concluded that the left auditory cortex is involved in phonemic discrimination. Subsequent studies replicated this finding for Japanese [37] and English [38] participants. These results suggest that the phonemic change MMN might be a candidate intermediate phenotype useful in research.

\section{Plasma Glutamate Level as an Environmental Factor}

Affecting the Duration Change MMNm Latency

We observed a low ICC value for MMNm latency similarities in both MZ and DZ twin pairs, but the differences of MMNm latency in the phonemic change condition and pure-tone duration change condition tended to correlate with the difference of plasma amino acids within MZ pairs, while no significant correlation was observed after the Bonferroni correction. Duration-deviant MMN is considered more suitable as an index of vulnerability in SZ than frequency-deviant MMN because the amplitude reduction was larger in the former than in the latter [39]. Therefore, it is plausible to associate the amplitude reduction with the glutamate difference in the duration-deviant condition.

Changes in MMNm latency observed in several psychiatric disorders, including in SZ [40] and bipolar disorder [41], indicate dysfunctional glutamatergic neurotransmission. MMN latency is considered as an index of the time needed to recognize that a particular stimulus is not the same as the preceding stimuli [42]. Based on the adaptation hypothesis of the MMN, the latency may be dependent on the temporal responsiveness of the relevant neuronal population in the auditory cortex [43]. Javitt [44] proposed that changes in latency in patients with SZ may reflect dysfunction in the early bottom-up processing of sensory inputs.

In patients with SZ, some studies reported shortened $[45,46]$ and prolonged MMN latencies [23, 47], while others did not observe a difference [48]. These disparate results might be because glutamate levels in the brain of subjects with SZ vary depending on an individual's clinical course. The glutamine/glutamate ratio has a key role as part of the glutamate-glutamine cycle in neuron-glia communication, and it has been suggested that an abnormality in glutamate-glutamine cycling in the brain typifies patients with SZ $[49,50]$. In fact, glutamate + glutamine reductions in the medial prefrontal cortex were only found in patients with chronic SZ [51]. Furthermore, ketamine administration to mice is known to increase the N40 latency and abolish a subsequent deviance-elicited component between 50 and $75 \mathrm{~ms}$, which is analogous to N100 and MMN in humans [52]. One of the reasons for inconsistent MMN latencies is that this measurement can be influenced by changes in glutamate levels and the glutamate-glutamine cycling in the brain. Recently, several studies have reported an association between glutamatergic neurotransmission inferred using MRS and ERP. Kompus et al. [53] have shown that subjects with higher glutamate + glutamine in the superior temporal lobe have a shorter peak latency of the duration MMN. In this regard, however, the relationship between measures of glutamate in the plasma and H-MRS measures of glutamate in the brain remains to be established and requires further investigation.

The lack of a significant association between amino acid levels and the frequency-deviant MMN might be explained by the difference in the task paradigm, but the exact reason is unknown. Unlike duration-deviant MMN, frequency-deviant MMN does not tend to be significantly reduced in patients with SZ compared to healthy controls $[39,54]$.

It is known that NMDA receptor blockade reduces the MMN. Moreover, many studies have pointed to possible involvement of nicotinic, dopaminergic, muscarinic, GABAergic, and serotoninergic receptors in this phenomenon [55]. In consideration of this, we should entertain the possibility that all these pathways contribute to MMNm generation. 
The Effects of the Differences in an Experimental

Condition on MMNm Variables

Speech sound MMNm reflects long-term memory and native language. The participants in the present study were native Japanese speakers. The heritability of language is comparatively high, and genetic factors influence linguistic abilities in particular [56]. The left hemisphere of the brain is recognized as dominant for language. Therefore, there is convincing precedent for the high ICC of the maximum mGFP strength of the phonemic MMNm seen in the left hemisphere in the current study. On the other hand, pure-tone MMNm reflects short-term discrimination learning. Past studies have pointed out that frequency-deviant MMNm represents transient refractoriness in neurons [57], while duration-deviant MMNm represents a memory-based process. A change in the number of glutamate receptors with learning, which leads to changes in synaptic transmission efficiency [58], is considered the basic process in memory formation and extinction in the brain. The present association between duration-deviant MMN and glutamate might reflect the effects of glutamate involvement in memory formation.

The present results show lower correlation values in the duration and frequency MMNm than do those of a previous twin study [8]. The analysis methods used with the MEG data potentially affected the results. The GFP was computed based on many sensors, and MMNm latency might have differed across channels. In addition, the strength of the MMNm showed higher ICC values than did the latency. This is comparable to the finding of Hall et al. [8] with low test-retest reliability. These results suggest that latency might be more variable than mGFP peak strength. The associations of plasma glutamate and glutamate/glutamine were shown with mGFP latency in the tone duration change condition but not in the phonemic change condition. The speech sound MMN has a partly different origin from the pure-tone MMN. The frontal cortex plays an attentional and/or top-down role in the modulatory control of speech sound processing [59], while interest in this study focused on the temporal region. Both temporal and frontal regions contributed to the EEG recording, while only the temporal source contributed to the MEG because MEG cannot detect the frontal field generated by a radial source.

\section{Limitations}

Several limitations should be considered when interpreting our results. Firstly, the number of twin pairs, particularly DZ twin pairs, was relatively small. The setting of the sample size was determined according to Hall et al.
[8]. The number of MZ pairs was comparable to the previous twin study using $M M N$, while that of $D Z$ pairs was insufficient. Therefore, we could not perform a structural equation modelling analysis, and the present results showed significant differences after Bonferroni correction in the correlation between the absolute values of the MMNm indices and the amino acid values. In addition, most participants were female. Moreover, some twin pairs could not participate in the measurement of the levels of amino acids in the peripheral blood. The present results need to be replicated in a larger twin sample that includes more males and DZ pairs. Secondly, we focused on the RMS analysis and did not use the equivalent current dipole (ECD) data because the ECD analysis could not estimate the generator for all participants. However, the MMNm variables by RMS and ECD were positively correlated in all conditions ( $\mathrm{n}=66-76$; mGFP strength, $\rho=0.34-0.76$; latency, $\rho=0.22-0.59$ ). We adopted the mGFP of the MMNm in step with a series of our studies $[40,41,60]$, which uses the mean waveform from multiple channels. That has the potential to lower the ICCs. Further study is needed with a more detailed analysis of single channels. In addition, because the MMNm is the MMN difference waveform, there is a possibility that a difference in $\mathrm{MMNm}$ latency might arise from a latency change in one of these responses or in both of them. Further analysis using the response waveform of each stimulus could elucidate the heritability of MMNm and its association with plasma amino acids. Thirdly, plasma glutamate level may not directly reflect glutamate activity in the brain. The relationship between plasma amino acid levels and CSF levels should be clarified in animal studies. The intra-pair differences in MMNm are affected by a variety of environmental factors including foetal development, childbirth, various experiences during life, and plasma glutamate at the time of MEG measurement. Comprehensive analyses of these factors are required, and correlations between individual MMNm values and plasma analyte levels across individuals should be examined in order to address whether these measures exhibit any correlation in the general population. These limitations require greater consideration in the future.

\section{Conclusion}

In conclusion, we investigated $\mathrm{MMNm}$ heritability and the association between the MMNm index and plasma amino acid levels in healthy adult twins. MMNm peak strength showed moderate-to-high heritability, but 
MMNm latency in all experimental conditions indicated low heritability in MZ twin pairs. The peak strength of phonemic MMNm in the left hemisphere in MZ twins exhibited a high ICC compared with DZ twins. In addition, the latency difference within twin pairs tended to be associated with the difference in the plasma amino acid levels. These results indicate that MMNm may be a promising biomarker related to the pathophysiology of psychiatric disorders such as SZ. However, the present results need to be replicated in a large twin sample.

\section{Acknowledgments}

We would like to thank the participants in this study, Dr Kenji Itoh for his technical assistance in creating the speech sound stimuli, and Mr Satoshi Eguchi, Dr Ayaka Ishii-Takahashi, Ms Hitomi Ito, Dr Norichika Iwashiro, Dr Akihide Kinoshita, Dr Masaru Kinou, Mr Kenji Kohata, Dr Shinsuke Koike, Dr Toshiaki Kono, Dr Hitoshi Kuwabara, Dr Kohei Marumo, Dr Junko Matsubayashi, Dr Tatunobu Natsubori, Dr Nao Nishida, Dr Shiho Okuhata, Dr Eisuke Sakakibara, Dr Yoshihiro Satomura, Ms Chie Shimojo, Dr Mamoru Tochigi, Dr Katsushi Tokunaga, Dr Yosuke Takano, Ms Aki Takei, Dr Syudo Yamasaki, and Dr Hidenori Yamasue for their substantial support of the twin research project at the Department of Neuropsychiatry, The University of Tokyo. We thank Ms Yuko Fujita for her technical assistance with amino acid measurements.
This work was supported by a Grant-in-Aid for Scientific Research on Innovative Areas (23118001 and 23118004; Adolescent Mind and Self-Regulation to K.K.), the Brain/MINDS project, and a Grant-in-Aid for Young Scientists (B) (26860915 to Y.N.) from the MEXT/AMED/JSPS of Japan.

\section{Statement of Ethics}

All participants provided written informed consent prior to participation. The ethical committee of the Faculty of Medicine, The University of Tokyo, approved this study (No. 784-2 for the MEG experiment; No. 2094-5 for the amino acid measurements; No. 2450-2 for twin research). This study was conducted in accordance with the ethical standards set forth in the Declaration of Helsinki.

\section{Disclosure Statement}

We would like to disclose potential conflicts of interest regarding all financial support for the present study. Dr. Yukika Nishimura was engaged during this study at The University of Tokyo until the end of March 2015. She is now employed by Japan Agency for Medical Research and Development (AMED) and a contracted researcher at The University of Tokyo. The Agency had no role in the design and conduct of the study; data collection, analysis, or interpretation; or in preparation, review, or approval of the manuscript. All other authors have no relevant conflicts of interest.

\section{References}

1 Naatanen R, Kahkonen S: Central auditory dysfunction in schizophrenia as revealed by the mismatch negativity (MMN) and its magnetic equivalent MMNm: a review. Int J Neuropsychopharmacol 2009;12:125-135.

2 Umbricht D, Krljes S: Mismatch negativity in schizophrenia: a meta-analysis. Schizophr Res 2005;76:1-23.

3 Salisbury DF, Kuroki N, Kasai K, Shenton ME, McCarley RW: Progressive and interrelated functional and structural evidence of post-onset brain reduction in schizophrenia. Arch Gen Psychiatry 2007;64:521-529.

4 Nagai T, Tada M, Kirihara K, Yahata N, Hashimoto R, Araki T, Kasai K: Auditory mismatch negativity and $\mathrm{P} 3 \mathrm{a}$ in response to duration and frequency changes in the early stages of psychosis. Schizophr Res 2013;150: 547-554.

5 Jessen F, Fries T, Kucharski C, Nishimura T, Hoenig K, Maier W, Falkai P, Heun R: Amplitude reduction of the mismatch negativity in first-degree relatives of patients with schizophrenia. Neurosci Lett 2001;309:185-188.
6 Michie PT, Innes-Brown H, Todd J, Jablensky AV: Duration mismatch negativity in biological relatives of patients with schizophrenia spectrum disorders. Biol Psychiatry 2002;52: 749-758.

7 Bramon E, Croft RJ, McDonald C, Virdi GK, Gruzelier JG, Baldeweg T, Sham PC, Frangou S, Murray RM: Mismatch negativity in schizophrenia: a family study. Schizophr Res 2004; 67:1-10.

8 Hall MH, Schulze K, Rijsdijk F, Picchioni M, Ettinger U, Bramon E, Freedman R, Murray RM, Sham P: Heritability and reliability of P300, P50 and duration mismatch negativity. Behav Genet 2006;36:845-857.

9 Javitt DC, Steinschneider M, Schroeder CE, Arezzo JC: Role of cortical $N$-methyl-D-aspartate receptors in auditory sensory memory and mismatch negativity generation: implications for schizophrenia. Proc Natl Acad Sci USA 1996;93:11962-11967.

10 Kawakubo Y, Suga M, Tochigi M, Yumoto M, Itoh K, Sasaki T, Kano Y, Kasai K: Effects of metabotropic glutamate receptor 3 genotype on phonetic mismatch negativity. PLoS One 2011;6:e24929.
11 Konradi C, Heckers S: Molecular aspects of glutamate dysregulation: implications for schizophrenia and its treatment. Pharmacol Ther 2003;97:153-179.

12 Marsman A, van den Heuvel MP, Klomp DW, Kahn RS, Luijten PR, Hulshoff Pol HE: Glutamate in schizophrenia: a focused review and meta-analysis of ${ }^{1} \mathrm{H}$-MRS studies. Schizophr Bull 2013;39:120-129.

13 Alfredsson G, Wiesel FA, Tylec A: Relationships between glutamate and monoamine metabolites in cerebrospinal fluid and serum in healthy volunteers. Biol Psychiatry 1988; 23:689-697.

14 McGale EH, Pye IF, Stonier C, Hutchinson EC, Aber GM: Studies of the inter-relationship between cerebrospinal fluid and plasma amino acid concentrations in normal individuals. J Neurochem 1977;29:291-297.

15 Palomino A, Gonzalez-Pinto A, Aldama A, Gonzalez-Gomez C, Mosquera F, GonzalezGarcia G, Matute C: Decreased levels of plasma glutamate in patients with first-episode schizophrenia and bipolar disorder. Schizophr Res 2007;95:174-178. 
16 Hashimoto K, Fukushima T, Shimizu E, Komatsu N, Watanabe H, Shinoda N, Nakazato M, Kumakiri C, Okada S, Hasegawa H, Imai K, Iyo M: Decreased serum levels of Dserine in patients with schizophrenia: evidence in support of the $N$-methyl-D-aspartate receptor hypofunction hypothesis of schizophrenia. Arch Gen Psychiatry 2003;60:572576.

17 Frye MA, Tsai GE, Huggins T, Coyle JT, Post RM: Low cerebrospinal fluid glutamate and glycine in refractory affective disorder. Biol Psychiatry 2007;61:162-166.

18 Hashimoto K, Engberg G, Shimizu E, Nordin C, Lindstrom LH, Iyo M: Elevated glutamine/ glutamate ratio in cerebrospinal fluid of first episode and drug naive schizophrenic patients. BMC Psychiatry 2005;5:6.

19 Draisma HH, Beekman M, Pool R, van Ommen GJ, Adamski J, Prehn C, Vaarhorst AA, de Craen AJ, Willemsen G, Slagboom PE, Boomsma DI: Familial resemblance for serum metabolite concentrations. Twin Res Hum Genet 2013;16:948-961.

20 Menni C, Zhai G, Macgregor A, Prehn C, Romisch-Margl W, Suhre K, Adamski J, Cassidy A, Illig T, Spector TD, Valdes AM: Targeted metabolomics profiles are strongly correlated with nutritional patterns in women. Metabolomics 2013;9:506-514.

21 Naatanen R, Lehtokoski A, Lennes M, Cheour M, Huotilainen M, Iivonen A, Vainio M, Alku P, Ilmoniemi RJ, Luuk A, Allik J, Sinkkonen J, Alho K: Language-specific phoneme representations revealed by electric and magnetic brain responses. Nature 1997;385:432-434.

22 Kasai K, Nakagome K, Itoh K, Koshida I, Hata A, Iwanami A, Fukuda M, Kato N: Impaired cortical network for preattentive detection of change in speech sounds in schizophrenia: a high-resolution event-related potential study. Am J Psychiatry 2002;159:546-553.

23 Kasai K, Yamada H, Kamio S, Nakagome K, Iwanami A, Fukuda M, Yumoto M, Itoh K, Koshida I, Abe O, Kato N: Neuromagnetic correlates of impaired automatic categorical perception of speech sounds in schizophrenia. Schizophr Res 2003;59:159-172.

24 Oldfield RC: The assessment and analysis of handedness: The Edinburgh Inventory. Neuropsychologia 1971;9:97-113.

25 Sheehan DV, Lecrubier Y, Sheehan KH, Amorim P, Janavs J, Weiller E, Hergueta T, Baker R, Dunbar GC: The Mini-International Neuropsychiatric Interview (m.I.N.I.): the development and validation of a structured diagnostic psychiatric interview for DSM-IV and ICD-10. J Clin Psychiatry 1998;59(suppl 20):22-33; quiz 34-57.

26 Ooki S, Yamada K, Asaka A: Zygosity diagnosis of twins by questionnaire for twins' mothers. Acta Genet Med Gemellol (Roma) 1993; 42:17-22.
27 Ooki S, Yamada K, Asaka A, Hayakawa K: Zygosity diagnosis of twins by questionnaire. Acta Genet Med Gemellol (Roma) 1989;39: 109-115.

28 Matsuoka K, Uno M, Kasai K, Koyama K, Kim Y: Estimation of premorbid IQ in individuals with Alzheimer's disease using Japanese ideographic script (Kanji) compound words: Japanese version of national adult reading test. Psychiatry Clin Neurosci 2006; 60:332-339.

29 Sakakibara E, Takizawa R, Nishimura Y, Kawasaki S, Satomura Y, Kinoshita A, Koike S, Marumo K, Kinou M, Tochigi M, Nishida N, Tokunaga K, Eguchi S, Yamasaki S, Natsubori T, Iwashiro N, Inoue H, Takano Y, Takei K, Suga M, Yamasue H, Matsubayashi J, Kohata K, Shimojo C, Okuhata S, Kono T, Kuwabara H, Ishii-Takahashi A, Kawakubo Y, Kasai K: Genetic influences on prefrontal activation during a verbal fluency task in adults: a twin study based on multichannel near-infrared spectroscopy. Neuroimage 2014;85Pt:508517.

30 Fukushima T, Kawai J, Imai K, Toyo'oka T: Simultaneous determination of D- and L-serine in rat brain microdialysis sample using a column-switching HPLC with fluorimetric detection. Biomed Chromatogr 2004;18:813819.

31 Hashimoto K, Sawa A, Iyo M: Increased levels of glutamate in brains from patients with mood disorders. Biol Psychiatry 2007;62: 1310-1316.

32 Matsubayashi J, Kawakubo Y, Suga M, Takei Y, Kumano S, Fukuda M, Itoh K, Yumoto M, Kasai K: The influence of gender and personality traits on individual difference in auditory mismatch: a magnetoencephalographic (MMNm) study. Brain Res 2008;1236:159165.

33 Takei Y, Kumano S, Hattori S, Uehara T, Kawakubo Y, Kasai K, Fukuda M, Mikuni M: Preattentive dysfunction in major depression: a magnetoencephalography study using auditory mismatch negativity. Psychophysiology 2009;46:52-61.

34 Tervaniemi M, Kujala A, Alho K, Virtanen J, Ilmoniemi RJ, Naatanen R: Functional specialization of the human auditory cortex in processing phonetic and musical sounds: a magnetoencephalographic (MEG) study. Neuroimage 1999;9:330-336.

35 Sham P: Statistics in Human Genetics. London, Arnold, 1998.

36 Hall MH, Schulze K, Bramon E, Murray RM, Sham P, Rijsdijk F: Genetic overlap between P300, P50, and duration mismatch negativity. Am J Med Genet B Neuropsychiatr Genet 2006;141B:336-343.

37 Koyama S, Gunji A, Yabe H, Oiwa S, Akahane-Yamada R, Kakigi R, Naatanen R: Hemispheric lateralization in an analysis of speech sounds. Left hemisphere dominance replicated in Japanese subjects. Brain Res Cogn Brain Res 2000;10:119-124.
38 Alho K, Connolly JF, Cheour M, Lehtokoski A, Huotilainen M, Virtanen J, Aulanko R, Ilmoniemi RJ: Hemispheric lateralization in preattentive processing of speech sounds. Neurosci Lett 1998;258:9-12.

39 Michie PT, Budd TW, Todd J, Rock D, Wichmann H, Box J, Jablensky AV: Duration and frequency mismatch negativity in schizophrenia. Clin Neurophysiol 2000;111:10541065.

40 Kasai K, Hashimoto O, Kawakubo Y, Yumoto M, Kamio S, Itoh K, Koshida I, Iwanami A, Nakagome K, Fukuda M, Yamasue H, Yamada H, Abe O, Aoki S, Kato N: Delayed automatic detection of change in speech sounds in adults with autism: a magnetoencephalographic study. Clin Neurophysiol 2005;116: 1655-1664.

41 Takei Y, Kumano S, Maki Y, Hattori S, Kawakubo Y, Kasai K, Fukuda M, Mikuni M: Preattentive dysfunction in bipolar disorder: a MEG study using auditory mismatch negativity. Prog Neuropsychopharmacol Biol Psychiatry 2010;34:903-912.

42 Picton TW, Alain C, Otten L, Ritter W, Achim A: Mismatch negativity: different water in the same river. Audiol Neurootol 2000;5:111139

43 May PJ, Tiitinen H: Mismatch negativity (MMN), the deviance-elicited auditory deflection, explained. Psychophysiology 2010; 47:66-122.

44 Javitt DC: Sensory processing in schizophrenia: neither simple nor intact. Schizophr Bull 2009;35:1059-1064.

45 Domjan N, Csifcsak G, Drotos G, Janka Z, Szendi I: Different patterns of auditory information processing deficits in chronic schizophrenia and bipolar disorder with psychotic features. Schizophr Res 2012;139:253-259.

46 Kargel C, Sartory G, Kariofillis D, Wiltfang J, Muller BW: Mismatch negativity latency and cognitive function in schizophrenia. PLoS One 2014;9:e84536.

47 Kathmann N, Wagner M, Rendtorff N, Engel RR: Delayed peak latency of the mismatch negativity in schizophrenics and alcoholics. Biol Psychiatry 1995;37:754-757.

48 Murphy JR, Rawdon C, Kelleher I, Twomey D, Markey PS, Cannon M, Roche RA: Reduced duration mismatch negativity in adolescents with psychotic symptoms: further evidence for mismatch negativity as a possible biomarker for vulnerability to psychosis. BMC Psychiatry 2013;13:45.

49 Hashimoto K: Abnormalities of the glutamine-glutamate-GABA cycle in the schizophrenia brain. Schizophr Res 2014;156:281282.

50 Hashimoto K: Targeting of NMDA receptors in new treatments for schizophrenia. Expert Opin Ther Targets 2014;18:1049-1063. 
51 Natsubori $\mathrm{T}$, Inoue $\mathrm{H}$, Abe $\mathrm{O}$, Takano $\mathrm{Y}$, Iwashiro N, Aoki Y, Koike S, Yahata N, Katsura M, Gonoi W, Sasaki H, Takao H, Kasai $\mathrm{K}$, Yamasue H: Reduced frontal glutamate + glutamine and $\mathrm{N}$-acetylaspartate levels in patients with chronic schizophrenia but not in those at clinical high risk for psychosis or with first-episode schizophrenia. Schizophr Bull 2014;40:1128-1139.

52 Ehrlichman RS, Maxwell CR, Majumdar S, Siegel SJ: Deviance-elicited changes in eventrelated potentials are attenuated by ketamine in mice. J Cogn Neurosci 2008;20:1403-1414.

53 Kompus K, Westerhausen R, Craven AR, Kreegipuu K, Poldver N, Passow S, Specht K, Hugdahl K, Naatanen R: Resting-state glutamatergic neurotransmission is related to the peak latency of the auditory mismatch negativity (MMN) for duration deviants: $\mathrm{An}^{1}{ }^{1} \mathrm{H}-$ MRS-EEG study. Psychophysiology 2015;52: 1131-1139.

54 Nagai T, Tada M, Kirihara K, Araki T, Jinde $\mathrm{S}$, Kasai K: Mismatch negativity as a 'translatable' brain marker toward early intervention for psychosis: a review. Front Psychiatry 2013; 4:115.

55 Garrido MI, Kilner JM, Stephan KE, Friston KJ: The mismatch negativity: a review of underlying mechanisms. Clin Neurophysiol 2009;120:453-463.

56 Stromswold K: Why aren't identical twins linguistically identical? Genetic, prenatal and postnatal factors. Cognition 2006;101:333384.
57 Naatanen R, Picton T: The N1 wave of the human electric and magnetic response to sound: a review and an analysis of the component structure. Psychophysiology 1987;24:375-425.

58 Bredt DS, Nicoll RA: AMPA receptor trafficking at excitatory synapses. Neuron 2003;40: 361-379.

59 Alho K, Woods DL, Algazi A, Knight RT, Naatanen R: Lesions of frontal cortex diminish the auditory mismatch negativity. Electroencephalogr Clin Neurophysiol 1994;91:353-362.

60 Suga M, Nishimura Y, Kawakubo Y, Yumoto $\mathrm{M}$, Kasai K: MEG recording of auditory mismatch negativity in response to duration and frequency deviants in a single session in patients with schizophrenia. Psychiatr Clin Neurosci 2016;70:295-302. 